\title{
Symmetry in Engineering Sciences
}

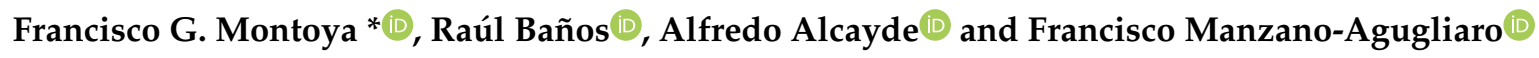 \\ Department of Engineering, University of Almeria, ceiA3, 04120 Almeria, Spain; rbanos@ual.es (R.B.); \\ aalcayde@ual.es (A.A.); fmanzano@ual.es (F.M.-A.) \\ * Correspondence: pagilm@ual.es; Tel.: +34-950-015791; Fax: +34-950-015491
}

Received: 13 June 2019; Accepted: 13 June 2019; Published: 15 June 2019

\begin{abstract}
The symmetry concept is mainly used in two senses. The first from the aesthetic point of view of proportionality or harmony, since human beings seek symmetry in nature. Or the second, from an engineering point of view to attend to geometric regularities or to explain a repetition process or pattern in a given phenomenon. This special issue dedicated to geometry in engineering deals with this last concept, which aims to collect both the aspects of geometric solutions in engineering, which may even have a certain aesthetic character, and the aspect of the use of patterns that explain observed phenomena.
\end{abstract}

Keywords: asymmetry; synchronization; topology; electrical circuits; electronic devices; mechanical structures; robots; graphic modelling; complex networks; optimization; computing applications

\section{Introduction}

Symmetry is a frequent pattern widely studied in different research fields. In particular, complex systems with symmetry arise in engineering science (e.g., in mechanical engineering, symmetric and synchronized systems are often used to satisfy stability criteria for rotating structures; in electrical engineering, the study of symmetrical and asymmetrical faults in power systems is a critical issue; in telecommunications engineering, many systems are symmetrical since data speed or quantity is the same in both directions; in civil engineering, the strength of the objects depend on the symmetry; in computer engineering, symmetric network structures and symmetric algorithms are often studied, etc.).

This Special Issue invites researchers to submit original research papers and review articles related to any engineering discipline where theoretical or practical issues of symmetry are considered. The topics of interest include, but are not limited to:

- Symmetry in electrical and electronic engineering

- Symmetry in mechanical engineering

- Symmetry in automation and robotic engineering

- Symmetry in computer engineering

- Symmetry in telecommunications engineering

- Symmetry in civil engineering (transportation, hydraulics, etc.)

- Symmetry in chemical engineering

- Symmetry and topology of complex networks in engineering

- Symmetry and optimization in engineering applications

\section{Statistics of the Special Issue}

The statistics of the call for papers for this special issue related to published or rejected items was: Total submissions (19), Published (12; 73\%), and Rejected (7; 27\%). 
The authors' geographical distribution by country for published papers is shown in Table 1, where it is possible to observe 45 authors from five different countries. Note that it is usual for an article to be signed by more than one author and for authors to collaborate with others of different affiliations.

Table 1. Geographic distribution by the country of author.

\begin{tabular}{cc}
\hline Country & Number of Authors \\
\hline China & 31 \\
Spain & 8 \\
Pakistan & 3 \\
Czech Republic & 2 \\
Korea & 1 \\
\hline Total & 45 \\
\hline
\end{tabular}

\section{Authors of this Special Issue}

The authors of this special issue and their main affiliations are summarized in Table 2, where there are four authors on average per manuscript.

Table 2. Affiliations and bibliometric indicators for the authors.

\begin{tabular}{|c|c|c|}
\hline Author & Main Affiliation & Reference \\
\hline Cristina Velilla & Universidad Politécnica de Madrid & [1] \\
\hline Alfredo Alcayde & University of Almeria & [1] \\
\hline Carlos San-Antonio-Gómez & Universidad Politécnica de Madrid & [1] \\
\hline Francisco G. Montoya & University of Almeria & [1] \\
\hline Ignacio Zavala & Universidad Politécnica de Madrid & [1] \\
\hline Francisco Manzano-Agugliaro & University of Almeria & [1] \\
\hline José Ignacio Rojas-Sola & University of Jaen & [2] \\
\hline Eduardo De la Morena-De la Fuente & University of Jaen & [2] \\
\hline Yu Zhang & South China University of Technology & [3] \\
\hline Yuanpeng Zhu & South China University of Technology & [3] \\
\hline Xuqiao Li & South China University of Technology & [3] \\
\hline Xiaole Wang & South China University of Technology & [3] \\
\hline Xutong Guo & South China University of Technology & [3] \\
\hline Nasar Iqbal & University of Engineering and Technology & [4] \\
\hline Sadiq Ali & University of Engineering and Technology & [4] \\
\hline Imran Khan & University of Engineering and Technology & [4] \\
\hline Byung Moo Lee & Sejong University & [4] \\
\hline Ling Wang & Henan Agricultural University & [5] \\
\hline Dongfang Zhou & $\begin{array}{c}\text { National Digital Switching System Engineering and } \\
\text { Technology R\&D Center (NDSC) }\end{array}$ & [5] \\
\hline Hui Tian & Henan Agricultural University & [5] \\
\hline Hao Zhang & Henan Agricultural University & [5] \\
\hline Wei Zhang & Henan Agricultural University & [5] \\
\hline Yanrong Wang & Beihang University & [6] \\
\hline Hang Ye & Beihang University & [6] \\
\hline Xianghua Jiang & Beihang University & [6] \\
\hline Aimei Tian & Beihang University & [6] \\
\hline Daniel Chalupa & Brno University of Technology & [7] \\
\hline Jan Mikulka & Brno University of Technology & [7] \\
\hline Ke Ruan & Xi'an University of Architecture and Technology & [8] \\
\hline Qi Zhang & Xi'an University of Architecture and Technology & [8] \\
\hline Han-ye Zhang & Jiujiang University & [9] \\
\hline Wei-ming Lin & Jiujiang University & [9] \\
\hline Ai-xia Chen & Jiujiang University & [9] \\
\hline Siqi Liu & Beijing Jiaotong University & [10] \\
\hline Boliang Lin & Beijing Jiaotong University & [10] \\
\hline Jianping Wu & Beijing Jiaotong University & [10] \\
\hline
\end{tabular}


Table 2. Cont.

\begin{tabular}{ccc}
\hline Author & Main Affiliation & Reference \\
\hline Yinan Zhao & Beijing Jiaotong University & {$[10]$} \\
Jianjie Zheng & Dalian Jiaotong University & {$[11]$} \\
Yu Yuan & Dalian Jiaotong University & {$[11]$} \\
Li Zou & Dalian Jiaotong University & {$[11]$} \\
Wu Deng & Dalian Jiaotong University & {$[11]$} \\
Chen Guo & Dalian Jiaotong University & {$[11]$} \\
Huimin Zhao & Dalian Jiaotong University & {$[11]$} \\
Zihan Qu & Beijing Jiaotong University & {$[12]$} \\
Shiwei He & Beijing Jiaotong University & {$[12]$} \\
\hline
\end{tabular}

\section{Brief Overview of the Contributions to This Special Issue}

The analysis of the topics (Table 3) identifies or summarizes the research undertaken. This section classifies the manuscripts according to the topics proposed in the special issue. It was observed that there are four topics that have dominated the others: Symmetry in electrical and electronic engineering; Symmetry in mechanical engineering; Symmetry in computer engineering; and Symmetry in civil engineering (transportation).

Table 3. Topic analysis.

\begin{tabular}{cc}
\hline Topic & Number of Manuscripts \\
\hline Symmetry in electrical and electronic engineering & 2 \\
Symmetry in mechanical engineering & 2 \\
Symmetry in computer engineering & 2 \\
Symmetry in civil engineering (transportation, hydraulics, etc.) & 2 \\
Symmetry in automation and robotic engineering & 1 \\
Symmetry in telecommunications engineering & 1 \\
Symmetry and topology of complex networks in engineering & 1 \\
Symmetry and optimization in engineering applications & 1 \\
\hline Total & 12 \\
\hline
\end{tabular}

Author Contributions: All authors contributed equally to this work.

Conflicts of Interest: The authors declare no conflict of interest.

\section{References}

1. Velilla, C.; Alcayde, A.; San-Antonio-Gómez, C.; Montoya, F.G.; Zavala, I.; Manzano-Agugliaro, F. Rampant Arch and Its Optimum Geometrical Generation. Symmetry 2019, 11, 627. [CrossRef]

2. Rojas-Sola, J.I.; la Morena-De la Fuente, D. The Hay Inclined Plane in Coalbrookdale (Shropshire, England): Geometric Modeling and Virtual Reconstruction. Symmetry 2019, 11, 589. [CrossRef]

3. Zhang, Y.; Zhu, Y.; Li, X.; Wang, X.; Guo, X. Anomaly Detection Based on Mining Six Local Data Features and BP Neural Network. Symmetry 2019, 11, 571. [CrossRef]

4. Iqbal, N.; Ali, S.; Khan, I.; Lee, B.M. Adaptive Edge Preserving Weighted Mean Filter for Removing Random-Valued Impulse Noise. Symmetry 2019, 11, 395. [CrossRef]

5. Wang, L.; Zhou, D.; Tian, H.; Zhang, H.; Zhang, W. Parametric Fault Diagnosis of Analog Circuits Based on a Semi-Supervised Algorithm. Symmetry 2019, 11, 228. [CrossRef]

6. Wang, Y.; Ye, H.; Jiang, X.; Tian, A. A Prediction Method for the Damping Effect of Ring Dampers Applied to Thin-Walled Gears Based on Energy Method. Symmetry 2018, 10, 677. [CrossRef]

7. Chalupa, D.; Mikulka, J. A Novel Tool for Supervised Segmentation Using 3D Slicer. Symmetry 2018, 10, 627. [CrossRef]

8. Ruan, K.; Zhang, Q. Accessibility Evaluation of High Order Urban Hospitals for the Elderly: A Case Study of First-Level Hospitals in Xi'an, China. Symmetry 2018, 10, 489. [CrossRef] 
9. Zhang, H.Y.; Lin, W.M.; Chen, A.X. Path Planning for the Mobile Robot: A Review. Symmetry 2018, 10, 450. [CrossRef]

10. Liu, S.; Lin, B.; Wu, J.; Zhao, Y. Modeling the Service Network Design Problem in Railway Express Shipment Delivery. Symmetry 2018, 10, 391. [CrossRef]

11. Zheng, J.; Yuan, Y.; Zou, L.; Deng, W.; Guo, C.; Zhao, H. Study on a Novel Fault Diagnosis Method Based on VMD and BLM. Symmetry 2019, 11, 747. [CrossRef]

12. Qu, Z.; He, S. A Time-Space Network Model Based on a Train Diagram for Predicting and Controlling the Traffic Congestion in a Station Caused by an Emergency. Symmetry 2019, 11, 780. [CrossRef] 